\title{
La violencia en el noviazgo, la reacción estatal en la norma penal mexicana y su consideración desde el poder judicial.
}

\author{
Dating violence, the state's reaction to the Mexican criminal law and its \\ consideration from the judiciary. \\ Elisa Vázquez Sánchez ${ }^{a}$
}

\begin{abstract}
:
The diversity of forms in which human beings are related in affective contexts, many of them involving the use of technology and immersed in violent situations, generate a necessity for the Estate to constantly update the way in which it protects the asymmetries of power in courtship, aiming to eradicate gender violence.
\end{abstract}

Keywords:

violence, courtship, gender, legislation.

\section{Resumen:}

La diversidad de formas en que se relacionan los seres humanos en contextos afectivos, incluso a partir del uso de la tecnología, muchos de ellos inmersos en situaciones de violencia, generan que el Estado deba actualizar constantemente la manera en que protege las asimetrías de poder en el noviazgo, apuntando a erradicar la violencia de género.

\section{Palabras Clave:}

violencia, noviazgo, género, legislación.

\section{Introducción}

No cabe duda que con motivo de la violencia que hemos sufrido históricamente las mujeres, ha sido necesario contar con instrumentos y herramientas jurídicas a efecto de resolverlo. Inicialmente se contempló cómo al interior de los hogares mexicanos, se cuentan con altos índices de violencia, no obstante, no es con el matrimonio/concubinato como estas afectaciones empiezan, sino incluso antes (ENDIREH, 2016).

La Ley general de acceso a las mujeres a una vida libre de violencia (LGAMVLV), en su artículo 5, define la violencia contra las mujeres de la siguiente manera: "Cualquier acción u omisión, basada en su género, que les cause daño o sufrimiento psicológico, físico, patrimonial, económico, sexual o la muerte tanto en el ámbito privado como en el público"; por su parte, en el artículo 7, define la violencia familiar como: "el acto abusivo de poder u omisión intencional, dirigido a dominar, someter, controlar, o agredir de manera física, verbal, psicológica, patrimonial, económica y sexual a las mujeres, dentro o fuera del domicilio familiar, cuyo Agresor tenga o haya tenido relación de parentesco por consanguinidad o afinidad, de matrimonio, concubinato $o$ mantengan o hayan mantenido una relación de hecho"; de donde se advierte la importancia de tratar este tema.

La obligación que deviene de la firma y ratificación de tratados internacionales como lo son la Convención Sobre La Eliminación De Todas Las Formas De Discriminación Contra La Mujer (CEDAW) y la Convención Interamericana Para Prevenir, Sancionar $Y$ Erradicar La Violencia Contra La Mujer "Convención De Belem Do Pará", vigentes en nuestro país desde 1981 y 1999, respectivamente. De igual manera, se tuvo en consideración la necesidad de crear un andamiaje jurídico que brindara una adecuada protección a los derechos humanos de las mujeres y niñas, pues es la violencia de género lo que denota la gran desigualdad que se vive en México; la cual no solamente se traduce en un problema de seguridad pública o de salud, sino también lo es de discriminación, que debe ser erradicado, no solamente por vulnerar el artículo 1 de nuestra carta 
magna, sino también por un tema de justicia. Esta afectación no solamente tiene consecuencias en el contexto social, me refiero a las relaciones de pareja mal logradas, sino que es tan grave que el propio Banco Interamericano de Desarrollo (MORRISON, 1999), ha señalado que la violencia en contra de las mujeres implica graves costos, algunos de los cuales son cuantificables, al referirse a rubros como la salud, servicios legales y de protección, días de trabajo perdidos, merma en la productividad; mientras que otros tantos no lo son, como la afectación a los proyectos de vida, el cambio de hábitos, domicilios, las implicaciones en la salud mental y sus consecuencias, que, como sabemos, muchas veces no son tratados en los países de la región, o lo son de manera muy precaria, más, cuando se trata de personas con un contexto de pobreza que le limita la posibilidad de acceso a tratamientos de esta naturaleza.

Debemos tomar como referencia lo expresado en la Encuesta Nacional sobre Dinámica de las Relaciones en los Hogares de 2016 (INEGI), el 66.1\% de las mujeres mexicanas de 15 años o más, referimos eventos de violencia en algún momento de nuestra vida, predominando la violencia emocional, pero siendo constante también la violencia física, sexual y económica; y si bien, en su gran mayoría es en el contexto de una relación de pareja con convivencia (matrimonio/concubinato), donde en 2016 alcanzó el $57.1 \%$, también lo es que el $24.6 \%$ reportado en mujeres solteras (en relación distinta a matrimonio o concubinatounión libre), no es menor. (SIESVIM).

También resulta frecuente, acorde al citado instrumento, que en particular las más jóvenes opten por buscar apoyo en sus redes familiares o amistosas, no obstante, para poder hacer un frente real ante esta epidemia que aqueja las relaciones interpersonales, se requiere del trabajo conjunto de los Poderes de la unión en los tres niveles de gobierno. Es común que las personas cercanas recomienden a víctimas que dejen de estar ahí, que simplemente terminen esa relación, sin tomar en consideración que lo que se percibe, muchas veces no es más que la punta del iceberg y que detrás de las acciones que se observan, existen muchos factores que complejizan tomar decisiones contundentes dentro de esa relación. Pueden ser amenazas, extorsiones, dependencia económica, emocional, diversidad de trastornos inclusive (PRIETO MEDINA, 2014).

Está documentado, que las mujeres que han sido maltratadas a lo largo de su vida presentan diversas psicopatologías asociadas a estas conductas, como lo es el propio Síndrome de la mujer maltratada, definido por Ferreira (1992) como una adaptación a la situación aversiva caracterizada por el incremento de la habilidad de la persona para afrontar los estímulos adversos y minimizar el dolor, presenta también distorsiones cognitivas, como la minimización, negación o disociación; esto se asocia al cambio en la autopercepción, así como de los demás y del entorno.

Otra consecuencia se asocia con los síntomas del Trastorno de estrés postraumático generado por el abuso físico, sexual, psicológico, palpitaciones y pulso alterado, dificultades respiratorias, temblores incontrolables, desorientación, entre otros, incluso hasta llegar al Síndrome de Estocolmo (PRIETO MEDINA, 2014).

\section{Desarrollo}

Si bien existen importantes avances en el tema, es decir, acceso a la justicia, el Comité de la CEDAW, ha generado recomendaciones, pues no obstante la existencia de dos Protocolos para Juzgar con Perspectiva de Género, prevalecen prácticas y estructuras institucionales que dificultan el acceso de las mujeres a la justicia, los cuales se manifiestan, entre otras, como estereotipos discriminatorios, escasos conocimientos sobre los derechos de las mujeres por parte de los operadores jurídicos, parcialidad judicial y criterios interpretativos estereotipados (CEDAW/C/MEX/CO/9: 5).

\section{La respuesta del Estado Mexicano}

Se desprende que el Estado Mexicano ha implementado procedimientos para llevar adelante las Alertas de género ante el riesgo sistemático y generalizado que corren las mujeres en las diversas entidades de la República (INMUJERES, 2021). De igual manera, se pone en claro la dinámica en la que se cumple con el deber de debida diligencia por parte de las diversas autoridades de todo ámbito (OEA, 2007).

En el caso, derivado de las observaciones que nos han sido señaladas por el Comité para la eliminación de la discriminación contra la mujer (CEDAW, por sus siglas en inglés), los órganos jurisdiccionales realizan diversas capacitaciones y jornadas de actualización relacionadas con los temas de trascendencia para que los Juzgadores estén en aptitud de realizar su labor con perspectiva de género (ONU MUJERES, 2018).

Resulta igualmente importante, analizar cómo la legislación ha permeado estas dinámicas de violencia en el noviazgo, a efecto de garantizar una amplia protección a quien desde una relación de hecho, pueda ver afectados sus derechos humanos, en particular, el acceso a la justicia, su integridad física y en casos más graves, su propia vida.

No obstante, persiste la sensación de impunidad tratándose de acceso a la justicia en casos que implican violencia de género, tras revisar el Informe sobre las violencias de género en la procuración de justicia, realizado por la Comisión de Derechos Humanos de la 
Ciudad de México (CDHCDMX, 2019), así como las constantes marchas y protestas realizadas por las mujeres, encaminadas a visibilizar estos tipos de violencia, mismas que son constantes incluso a las afueras de los órganos ejecutivos y judiciales en cada ciudad.

Acorde a lo expresado por los trabajos de la organización México Evalúa a través de su documento "Derechos de los usuarios en el sistema de justicia" (2018), donde se hace referencia a la reforma que tuvo como origen el sistema penal acusatorio, al mencionar que "buscó proteger los derechos de las víctimas durante el proceso, se ha documentado la falta de materialización de estos objetivos, tanto en el ámbito federal como en el local", pues también precisa que "los delitos no denunciados, se mantiene en un nivel muy alto e incluso aumentó casi un punto porcentual en dos años al pasar de $92.8 \%$ a $93.7 \%$ (ENVIPE, INEGI). Esto confirma que los mexicanos siguen sin tener confianza en sus instituciones de seguridad y justicia para denunciar los delitos de los cuales fueron víctimas".

No debemos pasar por alto que cuando se trata de las mujeres, estos indicadores suelen arrojar números aún más alarmantes, pues la invisibilización de la problemática que se padece, aunado a la precariedad económica que aqueja a una importante parte de la población femenina (IMSLP, 2012) y más en contextos particulares como lo es la pandemia por COVID-19, hacen aún menos probable la denuncia y por lo tanto, la intervención jurisdiccional para efecto de tutela de derechos.

Resulta relevante analizar la legislación penal en cada Entidad Federativa, para advertir si tienen considerada la violencia en el noviazgo como delito, de donde se destaca que en algunas entidades se exige respecto a dichas relaciones de pareja, que hayan hecho o hagan vida en común (Baja California Sur, Campeche, Coahuila, Chiapas, Colima, Guanajuato, Guerrero, Jalisco, Nuevo León, Sinaloa); en otros casos, exigen al menos seis meses viviendo juntos o bien, reconocen la figura aún sin haber vivido juntos; no obstante, dejan fuera cuando viven juntos pero aún no cumplen con la temporalidad establecida, pues tampoco cae en la hipótesis diversa (Baja California, Ciudad de México, Tabasco, Veracruz); mientras que solamente en Oaxaca lo explicitan como violencia en el noviazgo, además, abre la puerta a otro tipo de relaciones como lo son de convivencia o similar. Algunas otras Entidades, permiten la relación de hecho en sí, o incluso se refieren a relación afectiva (Aguascalientes, Baja California, Chihuahua, Ciudad de México, Durango, Estado de México, Hidalgo, Michoacán, Morelos, Nayarit, Puebla, Querétaro, Quintana Roo, San Luis Potosí, Sonora, Tabasco, Tamaulipas, Tlaxcala, Yucatán y Veracruz).
La existencia de otros contextos donde se generan relaciones asimétricas entre hombres y mujeres, hizo necesario considerar reforzar la legislación estatal, para incluir la tutela de los derechos de las mujeres, en particular a vivir una vida libre de violencia en el contexto de relaciones de hecho o noviazgo, advirtiéndose que ya se encuentra plasmado en todas las entidades de nuestro país algún tipo penal que contempla esto, salvo Zacatecas.

\section{La tecnología y las nuevas formas de violentar en el noviazgo}

Se advierte también, que el uso de tecnologías y comunicaciones a distancia han coadyuvado tanto a la posibilidad de formar una pareja como a la de perpetuar la violencia a través de estas plataformas, siendo obligatorio para los juzgadores tomar en consideración estas circunstancias al momento de fundar y motivar sus decisiones.

Como se aprecia, en los marcos legales se establece de manera puntual los parámetros en los que se llevan adelante las relaciones interpersonales, en algunas legislaciones hay fórmulas abiertas que permiten el análisis de la relación per se, mientras que otras son más acotadas.

Se hace relevante considerar que la tecnología ha permeado no solamente en la manera en que nos conocemos, sino también en la que interactuamos (MORAL TORANZO, 2009), me refiero a esto, porque el uso de aplicaciones de manera cotidiana, si bien han acortado los tiempos de interacción y las distancias, han logrado que prevalezca la violencia y también los medios en que se ejerce e incluso difunde (APC, 2011). Los operadores del sistema de justicia, debemos tener bien abiertos los ojos, con la finalidad de advertir otras dinámicas menos cotidianas, donde se perpetúan estereotipos de género que pudieran pasar inadvertidos.

Ejemplo de ello, es la naturalización con que en tiempos actuales las personas conocen a alguien de manera virtual, establecen un nexo cotidiano por aplicaciones, el cual no escapa a los tintes de violencia familiar que se establecen cuando el trato es frente a frente, incluso al grado de generar actos de violencia en redes sociales o si llega a darse un encuentro físico.

Las formas más comunes de violentar por medios tecnológicos son el ciberacoso y hostigamiento online, el seguimiento de ubicaciones a partir de geolocalizadores, la exposición de fotos y videos íntimos, el empleo de estas herramientas para controlar, insultar y manipular a distancia, contacto no autorizado con amistades, familiares y compañeros de trabajo, ya sea a nombre de la víctima o bien, para evitar redes de apoyo, así como intimidar, denigrar, humillar (SAVE THE CHILDREN, 2019). 
Adicionalmente, incluso cuando las interacciones de origen hayan sido por medios reales, es en la web donde se generan los actos que vulneran derechos de las personas. Si bien existe ya un alto grado de aceptación y regulación atendiendo a la Ley Olimpia (SEGOB, 2020), también es cierto que hay otras tantas dinámicas que debemos visibilizar.

Es a partir de la perspectiva de género (art. $5 \mathrm{fr}$. II LGPIMYH) que estamos en condiciones de evaluar, caso a caso, ante qué nos enfrentamos. Como entes gubernamentales estamos obligados a identificar si existen desequilibrios de poder por razones de género, debemos desechar estereotipos y roles asignados, advertir la falta de neutralidad del derecho aplicable, en los casos en que se presente desventaja, tomar en cuenta los estándares de derechos humanos necesarios, e incluso, ordenar las probanzas necesarias ante la falta de material probatorio que sea de utilidad.

Son incontables las veces en que la falta de cuestionamientos a las personas afectadas, generan que no se catalogue de manera adecuada una violación a derechos humanos o un delito; coadyuvando así a que se perpetúe la impunidad a la que hice referencia al comienzo del texto.

En cuanto a análisis de casos, podemos advertir que en la legislación de la Ciudad de México, se puede otorgar el perdón, el cual se condiciona a un año sin violencia para surtir sus efectos (pone fin al proceso penal), sin embargo, solamente se refiere a la Violencia Familiar (art. 100 Código Penal), no así al delito diverso de la Violencia Familiar Equiparada (art. 201 bis Código Penal) que opera en casos de violencia en el noviazgo, por lo tanto, es necesario aplicar el referido deber de debida diligencia e interpretar que también aplica en este caso, aunque no esté explicitado, para así prevenir cualquier incidente, al menos por el año ya referido.

\section{Conclusiones}

Al retomar las ideas de párrafos previos, podemos hablar también de cómo las mencionadas relaciones de hecho, se consolidan también a partir de miedos tecnológicos, no nada más al conocer a las personas, sino también como mecanismo de comunicación, donde pese a la falta de cercanía física, se consolidan relaciones y no reconocer estos factores, 0 bien, como autoridades minimizarlos, limita la aplicación de la ley. Pues una pareja que se conoció por una aplicación para citas, ella mexicana y él francés, coincidieron durante dos años en diferentes viajes, hasta que estando en la Ciudad de México, él la golpeó y amenazó, donde se puso en duda la validez de la relación en sí, pues físicamente sólo habían estado en el mismo lugar, en total menos de un mes, con comunicación continua. Por lo tanto, existe tal dinámica de familiaridad $y$ afecto.

Es a partir de todos los frentes que debe atacarse este grave problema, el derecho evoluciona, sí, pero no a la velocidad que lo hace la sociedad y sus dinámicas, por lo tanto, debemos echar mano de todas las herramientas tanto legales como interpretativas, para lograr contrapesos a la violencia de género.

\section{Referencias}

Legislación Internacional

Convención sobre la Eliminación de todas las formas de Discriminación contra la Mujer, publicada en el Diario Oficial de la Federación, el martes 12 de mayo de 1981.

Convención Interamericana para Prevenir, Sancionar y Erradicar la Violencia contra la Mujer (también conocida como Convención Belém do Pará), publicada en la Primera Sección del Diario Oficial de la Federación, el martes 19 de enero de 1999.

Legislación Nacional

Ley General de Acceso de las Mujeres a una Vida Libre de Violencia, publicada en la Primera Sección del Diario Oficial de la Federación, el jueves 1 de febrero de 2007. Recomendaciones Generales.

Comité CEDAW, "La Violencia contra la Mujer", Recomendación General 19, 11을 periodo de sesiones (1992). Disponible en: «https://tbinternet.

ohchr.org/Treaties/CEDAW/Shared\%20Documents/1_Glo bal/INT_CEDAW_GEC_3731_S.pdf».

APC. (2011). El uso de la tecnología para perpetrar la violencia hacia las mujeres $-Y$ para combatirla. 5 de octubre de 2021, de Asociación para el Progreso de las comunicaciones Sitio web:

https://www.apc.org/sites/default/files/FactSheetVAWICTs _ES_0_1.pdf

CDHCDMX. COMISIÓN DE DERECHOS HUMANOS DE LA CIUDAD DE MÉXICO. (2019). Informe sobre las violencias de género en la procuración de justicia en la Ciudad de México. Ciudad de México: CDHDF.

"Derechos de los usuarios en el sistema de justicia. Ejercicio exploratorio.” México Evalúa, (2018), Primera Edición, México. https://www.mexicoevalua.org/mexicoevalua/wpcontent/uploads/2018/10/derechos-usuarios-sj.pdf

Encuesta Nacional sobre Dinámica de las Relaciones en los Hogares. https://www.inegi.org.mx/programas/endireh/2016/

IMSLP. Instituto De Las Mujeres Del Estado De San Luis Potosí. (2012). Modelo de Atención A Mujeres Víctimas de Violencia Familiar y de Género, Manual de operación. México: Instituto de las Mujeres de San Luis Potosí. 94.

INMUJERES. (2021). Alerta de Violencia de Género contra las Mujeres. 5 de octubre de 2021, de INMUJERES Sitio web: https://www.gob.mx/inmujeres/acciones-yprogramas/alerta-de-violencia-de-genero-contra-lasmujeres-80739 
Moral Toranzo,F. (2009). Internet como marco de comunicación e interacción social. Comunicar, $\mathrm{N}^{\circ} 32$ Vol. XVI, 231-237.

MORRISON, Andrew R y otro, (1999) "El Costo del Silencio. Violencia Doméstica en las Américas" Banco Interamericano de Desarrollo, Primera Edición en Español, New York.

OEA. Organización de los Estados Americanos. Relatoría sobre los derechos de la mujer. (2007). Acceso a la Justicia para Mujeres Víctimas de Violencia en las Américas. 6 de octubre de 2021, de OEA Sitio web: https://www.cidh.oas.org/women/acceso07/indiceacceso. $\mathrm{htm}$

ONU MUJERES. (2018). México ante la CEDAW. México: www.arteidiseno.cferreom. Sitio web: https://www.onu.org.mx/wpcontent/uploads/2019/04/MEXICO-ANTE-LA-CEDAW2018-web.pdf

Prieto Medina, María Carolina, (2014). Violencia de pareja. repercusiones en la salud mental de la mujer. Revista de enfermería C y L, Volumen 6 (2), 93-97.

Save the children. (2019). Violencia viral: los 9 tipos de violencia online. 5 de octubre de 2021, de Save the Children Sitio web: https://www.savethechildren.es/actualidad/violenciaviral-9-tipos-violencia-online

Secretaría de Gobernación. (2020). Ficha Técnica Ley Olimpia. 6 de octubre de 2021, de Gobierno de México Sitio web: http://ordenjuridico.gob.mx/violenciagenero/LEY\%20OLIM PIA.pdf

Ferreira, Graciela. (1992). Hombres violentos. Mujeres maltratadas: aportes a la investigación y tratamiento de un problema social. Buenos Aires: Sudamericana. 